\title{
Trophic interactions and ecological stability across coral reefs in the Marshall Islands
}

\author{
Peter Houk $^{1,2, *}$, Craig Musburger ${ }^{3}$ \\ ${ }^{1}$ University of Guam Marine Laboratory, Mangilao, Guam 96923, Guam \\ ${ }^{2}$ Pacific Marine Resources Institute, Saipan, Northern Mariana Islands \\ ${ }^{3}$ Department of Zoology, University of Hawaii at Manoa, Honolulu, Hawaii 96822, USA
}

\begin{abstract}
Coral reef assemblages, trophic interactions, and food web stability were examined across a remote and densely populated atoll, in the Republic of the Marshall Islands (RMI). The biomass of sharks, large-bodied piscivores, and secondary invertebrate consumers was expectedly larger in the absence of major human populations. Less intuitively, we report a doubling in the density and biomass of small-bodied acanthurids with significant human presence, whereas large-bodied parrotfishes were halved. These trends provided evidence for prey release of small acanthurids, but also indicated a reduction in grazing function given that power-law relationships govern fish size and physiology. Path analyses supported the conjecture that apex predator biomass enhanced the abundance of large-bodied herbivores, with ensuing benefits to calcifying benthic substrates and coral diversity. Human populations, as low as 40 individuals, had opposing linked interactions. The study next used species abundances to depict food chain interaction strengths, and multivariate measures of heterogeneity to depict food chain diversity. The removal of few strong links along the gradient of investigation (i.e. Acropora corals and sharks), as well as numerous weak links, was associated with fish assemblages and benthic substrates that had reduced grazing and calcification potential, respectively. The results inferred that a reduction in the functional response time of trophic guilds will follow perturbations (i.e. reduce stability), synonymous to food webs with low return rates to their modeled, stable configuration. This study provides a broader perspective for interpreting how humans and apex predators influence ecological stability across (RMI) coral reef ecosystems.
\end{abstract}

KEY WORDS: Remote atolls · Coral reef function - Anthropogenic effects · Trophic interactions · Top-down effects $\cdot$ Food webs $\cdot$ Apex predators

\section{INTRODUCTION}

Isolation of many of the world's most pristine coral reefs has hampered our ability to thoroughly examine ecological interactions that underpin these complex ecosystems in the absence of humans (Knowlton \& Jackson 2008). A notable attribute of food webs from many remote coral reef ecosystems is their inverted structure (Friedlander \& DeMartini 2002, Stevenson et al. 2007, Sandin et al. 2008, Friedlander et al. 2010), whereby long-lived apex predators constitute a disproportionate amount of the fish biomass and represent long-term carbon storage sinks with slow turnover rates (Rooney et al. 2006). These characteristics suggest that apex predators play a critical role in structuring coral reef ecosystems. Yet, empirical evidence for linked trophic interactions in their absence remains limited, and stems mainly from comparing coral reefs inside no-take marine protected areas (MPAs) with reefs that are fished at varying intensities (Mumby et al. 2006, 2007, McClanahan et al. 2007, Kellner et al. 2010). Clearly, MPAs can be effective fisheries management tools although even longstanding MPAs do not typically 
support large populations of influential top predators, such as sharks, that are found on remote reefs (McClanahan et al. 2007, Knip et al. 2012). As a result, deeper insight into the consequences of apex predator removal on coral reefs remains more theoretical than empirical.

Existing studies highlight an unintuitive, positive relationship between herbivore assemblages that are dominated by large-bodied species (i.e. species of surgeonfishes and parrotfishes that attain large reproductive and adult sizes) and the abundance of several piscivore predators. This relationship has been found along gradients of both fishing pressure (Mumby et al. 2006, Kellner et al. 2010) and rehabilitation following fishing closure (McClanahan et al. 2007). Consistent findings support that wellfounded, allometric relationships likely govern predator-to-prey, body-size ratios for coral reef ecosystems, and may serve as informative proxies of food chain interaction strengths (Emmerson \& Raffaelli 2004, Woodward et al. 2005). Human influences such as fishing pressure, which are known to act concomitantly across both predator and prey populations on coral reefs, may oppose the default interactions observed in 'natural' ecosystems. In light of this viewpoint, the present study revisits a fundamental question of coral reef ecology: What are the expected consequences of trophic 'downgrading' on coral reefs?

Food web models show that high apex predator abundances enhance the diversity of food chains that can stably coexist through time because they facilitate the distribution of high and low interaction strengths across a network of linkages (Bascompte et al. 2005, Rooney et al. 2006, Gross et al. 2009). It follows that trophic downgrading, or the removal of higher trophic levels, destabilizes food webs directly through dampening predator-prey cycles, but also indirectly through altered prey-resource interaction strengths in the absence of apex predators (Bascompte et al. 2005, Rooney et al. 2006, Estes et al. 2011, Rooney \& McCann 2011). Shifting food web dynamics have been shown to facilitate the establishment of less desirable and more opportunistic ecological states through a variety of cascading interactions (Estes et al. 2011). For coral reefs, this ultimately translates to fewer corals and calcifying organisms, and more algal and heterotrophic growth (Mumby et al. 2006, Nyström 2006). However, limited insight exists to determine and quantify (1) key trophic pathways, (2) how interaction strengths can be measured, and (3) what metrics might portray overall ecosystem stability.
The present study examined coral reef assemblages, trophic interactions, and indicators of food web stability across a remote (Rongelap) and densely populated (Majuro) atoll in the Republic of the Marshall Islands (RMI). We first characterized expected distinctions in coral reef assemblages between the atolls to establish a foundation for examining the degradation process. Relationships between species abundances, diversity patterns, and human presence were then quantified. The relative abundances of species were used to depict food chain interaction strengths, and multivariate measures of heterogeneity were used to depict food chain diversity because they represent useful indicators of food web stability that could be examined along our study gradient (Neutel et al. 2007, Rooney \& McCann 2011). Lastly, we performed structural equation modeling (i.e. path analysis) to test whether support existed for linked trophic interactions across humans, apex predators, herbivores, benthic substrates, and coral assemblages. Our approach provides a broader perspective for interpreting how key ecosystem drivers, humans and apex predators, may influence ecological stability on (RMI) coral reefs, and offers a framework to help determine thresholds required for ecosystem sustainability.

\section{MATERIALS AND METHODS}

\section{Study region and sampling design}

The RMI extends across a large portion of the central Pacific Ocean, including 29 coral atolls with lagoons ranging in size from 10 to over $2000 \mathrm{~km}^{2}$ (Fig. 1). Given their geographic isolation and low human population, abundant marine resources have been reported throughout many of the remote atolls (Beger et al. 2008). Yet, as the fisheries sector continues to develop and remote societies trade more of their resources for economic prosperity, improved monitoring and management is needed to ensure sustainability. To date, the existing doctrine surrounding RMI reefs describes the region in terms of species composition, distribution of macrofauna, and perceived condition (Wells 1954, Hiatt \& Strasburg 1960, Pinca et al. 2005, Beger et al. 2008, Richards et al. 2008).

Rongelap and Majuro Atolls were selected for study based upon their strong differences in human presence. Majuro is the capitol of the RMI with 25400 residents. Population density is highest in Delap, the urban center, and generally decreases with distance 
Fig. 1. Micronesia and the Marshall Islands highlighting the study sites (numbers in bottom panels), Majuro (pop. 25400 people) and Rongelap Atolls (pop. 40 people), with population centers denoted by stars
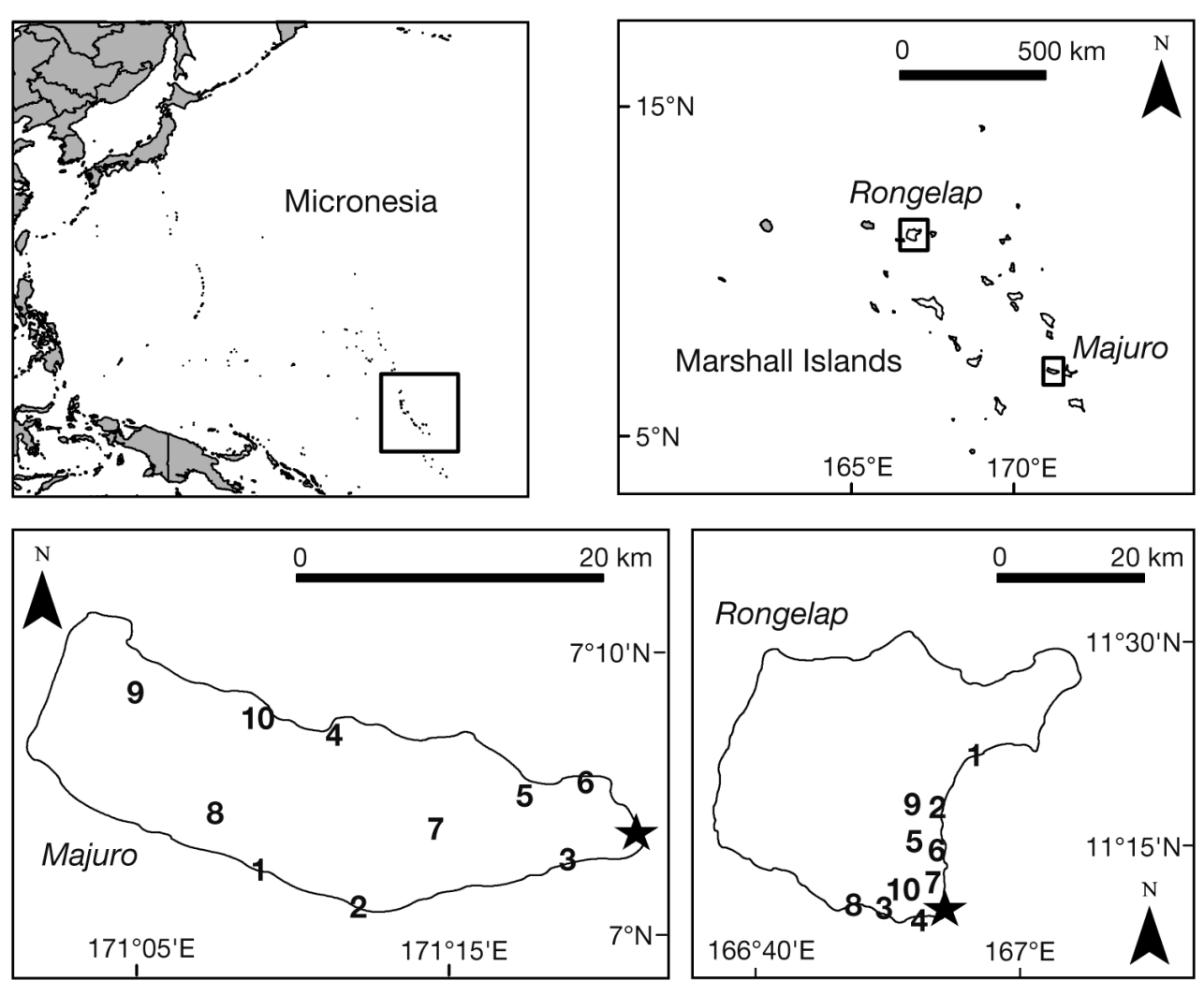

from town. Both nutrient enrichment and high fishery pressure are perceived concerns on Majuro Atoll, as residents place a strong reliance upon the urban center and marine resources for livelihoods and income generation (Pinca et al. 2005, Beger et al. 2008). In contrast, Rongelap Atoll has remained largely uninhabited for $57 \mathrm{yr}$ due to impacts associated with atomic bomb testing at Bikini Atoll in 1954 (Simon 1997). Currently, major clean-up efforts have been completed, and a resettlement process has begun. A population of approximately 40 construction workers resides on Rongelap while they are rebuilding the local infrastructure. These workers supplement their food imports with fresh reef fish caught primarily by hook-and-line, throw-net, and both day and nighttime spearfishing, exerting an unknown amount of fishing pressure on Rongelap's reefs. Land-based pollution is considered minimal given the sparse human population and limited infrastructure.

Within each atoll, 10 sites were established across patch, channel, and outer reefs, at similar scales of investigation ( $300 \mathrm{~km}^{2}$; Fig. 1). Coral, fish, and benthic assemblages were quantitatively assessed at the 5 to $8 \mathrm{~m}$ depth contour, along replicate $25 \mathrm{~m}$ transect lines ( $\mathrm{n}=6$ to 8 transect lines, depending upon habitat availability, as patch-reef size was limited at 2 sites). Coral species richness and abundances were estimated from ten $1 \times 1 \mathrm{~m}$ quadrats that were tossed haphazardly at equal intervals along the transect lines. Within each, all corals were identified to the species level, and the maximum diameter and the diameter perpendicular to the maximum were recorded for each discrete colony. Coral taxonomy followed Veron (2000). For analysis purposes, corals were also classified by growth form as encrusting, massive, low-relief, and high-relief. High-relief corals were defined by table-and-plate, staghorn, prostrate, and arborescent growth forms. Low-relief corals were defined by corymbose and compactcolumnar growth forms. From the measurements taken, surface area was assumed considering colonies were circular in nature. While the assumption of circularity may introduce some bias for highly branched species, this approach was consistent, and represents the most idealized universal assumption. Coral recruitment was estimated by the number of juvenile $(<5 \mathrm{~cm})$ corals belonging to 3 major reef building families that are predominantly broadcast spawners: Acroporidae, Pocilloporidae, and Faviidae (Baird et al. 2009). From these methods a total of 2988 coral colonies were measured, encompassing 33 genera and 141 species.

Fish assemblages were surveyed using a modified stationary point count (SPC) methodology (Bohnsack 
\& Bannerot 1986). Twelve replicate SPCs spaced at 15 to $20 \mathrm{~m}$ intervals were conducted at each site prior to any transect-based work. For each SPC, all target fish within a $5 \mathrm{~m}$ radius of the observer during a $3 \mathrm{~min}$ period were identified to the species level, counted, and size estimated (to the nearest $5 \mathrm{~cm}$ ). Target fish were categorized as acanthurids, scarids, serranids, carangids, labrids, lethrinids, lutjanids, balistids, kyphosids, mullids, and holocentrids that are known to be harvested. Sharks were also included. Size estimates were used to calculate biomass based on documented length-to-weight conversion factors (www.fishbase.org). For some analyses, species were grouped by trophic category based upon their reported diet (www.fishbase.org), and/or family. For generating estimates of mean herbivore/ detritivore size at each site, all fish below the $10 \mathrm{~cm}$ size bin were removed to avoid the potential influence of recruits. From these protocols, a total of 14680 target fish from 127 species and 24 families were observed.

Benthic substrate abundances were estimated from digital photographs that were taken at $1 \mathrm{~m}$ intervals along the transect lines. For each photograph, the substrate under 5 random points was assigned to a pre-defined category using the freely available computer software, Coral Point Count (Kohler \& Gill 2006). These methods yielded a total of 125 data points per transect and 500 to 1000 data points per site, resulting in high site-level statistical confidence (Houk \& van Woesik 2006). The benthic categories used for analysis were corals (typically genus level, but enhanced to include functional groupings within genera that constituted greater than $5 \%$ absolute coverage, such as Acropora 'tables', 'staghorn', or 'arborescent'), turf algae (less than $2 \mathrm{~cm}$ ), macroalgae (greater than $2 \mathrm{~cm}$, to genus level if abundant), fleshy coralline algae known to overgrow coral (Peyssonnelia spp., Pneophyllum spp.) (Keats et al. 1997, Antonius 1999, 2001), crustose coralline algae, sand, and other invertebrates (genus level if abundant). Finally, while 10 sites were selected for investigation on each atoll, benthic data were only collected from a subset of 7 on each atoll, due to logistical considerations.

\section{Data analyses}

Data were first analyzed to describe the nature and magnitude of coral and fish assemblages between Majuro and Rongelap using standard multivariate techniques (PRIMER software package; see Anderson et al. 2008 for methodology). Data were aggregated at the site level, log-transformed, and Bray-Curtis similarity matrices were generated to define the ecological distances between each pair of sites. Bray-Curtis similarity matrices were calculated by:

$$
\mathrm{S}_{(j, k)}=1-\left[\Sigma\left|\mathrm{Y}_{i j}-\mathrm{Y}_{i k}\right| / \Sigma\left(\mathrm{Y}_{i j}+\mathrm{Y}_{i k}\right)\right]
$$

where S represents the ecological similarity between the 2 sites $(j$ and $k$ ), $\Sigma$ (numerator) represents the summation of the absolute differences in the abundance of each species $\left(\mathrm{Y}_{i}\right)$ at the 2 sites, and $\Sigma$ (denominator) represents the sum of the abundances of species $\left(Y_{i}\right)$ at the 2 sites. Prior to examining interatoll differences, tests of multivariate homogeneity were conducted to determine if the Bray-Curtis similarities were evenly distributed among both atolls (PERMDISP tests). Significantly lower dispersion (i.e. multivariate variance) was found for both fish and coral assemblages on Rongelap (pseudo $t$-statistic $>2.6, \mathrm{p}<0.05$, PERMDISP, all assemblages). Given non-homogeneous variances, and the desire to explore variance structures on a similar standardized scale, multivariate comparisons were made using rank-transformed abundance data (ANOSIM tests), and visualized using non-metric, multi-dimensional scaling (MDS) plots. Low stress values associated with MDS plots (stress <0.25) suggest that the structure of multivariate datasets was accurately depicted within 2-dimensional space. Spearman correlations $(r>0.5)$ between individual species and the first 2 MDS-plot axes were used to highlight the species that contributed most to the observed multivariate trends. Given that Rongelap is nearly double the size of Majuro, sites on Rongelap were centered around the southwest sector of the atoll. To evaluate potential spatial autocorrelation among sites, correlations between geographic distances and BrayCurtis ecological distances were examined. No relationships existed for either atoll, suggesting sites were sufficiently separated to avoid significant influences of geographic clustering.

Standard pairwise testing was conducted for several components of the fish, benthic, and coral assemblages to build upon multivariate trends ( $t$-tests, Mann-Whitney $U$-tests if assumptions of normality or homogeneity were not met following Box-Cox transformations; Box \& Cox 1964). For examining sizeclass distributions of fishes and corals, KolmogorovSmirnov (K-S) tests were preferentially used because they explicitly test for differences between 2 sets of cumulative frequency data. 


\section{Multivariate heterogeneity}

Multivariate heterogeneity was next compared across and within the 2 atolls. We defined fish and coral assemblage heterogeneity by the mean BrayCurtis difference between sites (inter-site heterogeneity) and the mean Bray-Curtis difference between replicates within a site (intra-site heterogeneity). Reported above in Eq. (1), high Bray-Curtis similarity values indicated that species abundances were similarly distributed between sampling units (either between sites or between replicates within a site), while low values indicated less ecological similarity and greater taxonomic isolation. MDS plots and Spearman correlation analyses were used to visualize the multivariate patterns as noted above. Standard pairwise testing was used to examine whether inter-site and intra-site Bray-Curtis similarities differed between the atolls.

In order to exemplify the dependence of fish assemblage structure and biomass upon human presence, we conducted a series of regression analyses using distance from the sparse (40 people) human population on Rongelap as the dependent variable. First, intra-site fish assemblage heterogeneity was regressed against distance from humans. Because sharks were strong contributors to intra-site fish assemblage heterogeneity on Rongelap, we also regressed shark abundances against distance from humans. Finally, as a transition into our results describing linked trophic interactions, we also regressed mean herbivore/detritivore size (as a proxy of grazing potential) against distance from humans. Regression models were all inspected for independence and normality of residuals, and log-transformations of shark biomass were used to reduce skewness.

\section{Linked trophic interactions}

Structural equation modeling (i.e. path analysis) was undertaken to investigate whether the covariance structure between apex predators, human presence, herbivores/detritivores, benthic substrates, and coral assemblage dominance were linked in a predictable fashion that could define a trophic cascade. We used the package lavaan (Rosseel 2012) in R (R Development Core Team 2005) to test whether linked covariance structures were significantly different from independent counterparts. The trophic linkages examined were predefined by the body of knowledge describing ecological interactions on coral reefs: (1) apex predator biomass enhances herbivore/detritivore biomass and/or mean body size (Graham et al. 2005, Mumby et al. 2006, McClanahan et al. 2007), large herbivore/detritivore populations increase calcifying benthic substrates (Mumby et al. 2007, Lokrantz et al. 2008), and calcifying substrates facilitate coral recruitment and survival (Mumby et al. 2007, Houk et al. 2010), thus reducing coral assemblage dominance (Houk \& van Woesik 2010), (2) human presence reduces both apex predators and herbivores/detritivores through fishing (Myers et al. 2007, Ferretti et al. 2010), with similar ensuing relationships to the benthic and coral assemblages, and (3) human presence directly reduces favorable benthic substrates through the addition of land-based pollution (Smith et al. 2010), with similar ensuing relationships to coral assemblages (Fig. 2). Human presence was calculated as (distance from atoll's human population center $\times$ human population) + (distance from nearest point of any human presence $\times$ human population in the localized vicinity). Rongelap had a single population center so human presence was calculated by the linear distance from the sparse population multiplied by 40 people, as noted above for regression models. Prior to conducting path analyses all variables were logtransformed to account for skewness. Chi-square tests and comparative fit indices (CFI) were used to examine the degree of difference from independent models, with chi-square values greater than 0.05 (i.e. a poor fit with independent covariances) and CFI indices near 1 suggesting significance. Second, rootmean square errors (RMSE) were used to estimate the difference between the mean covariance residuals, whereby values close to 0 , with a cutoff of 0.05 , confirm significance.

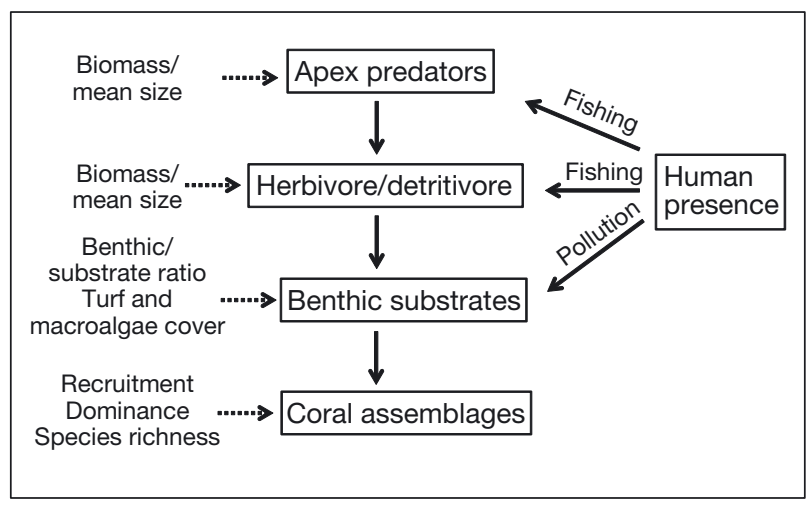

Fig. 2. Hypothesized trophic cascades investigated using path analyses. All combinations of the trophic guild attributes on the left hand side of the figure were examined; human presence was quantified as explained in 'Materials and methods: Linked trophic interactions' 


\section{RESULTS}

Expected differences in coral and fish species abundance patterns were observed between the atolls (ANOSIM R-statistic $>0.55, \mathrm{p}<0.001$; Fig. 3a,b). Biomass of sharks, large-bodied piscivores, and invertebrate consumers was larger on the sparsely inhabited atoll of Rongelap (Fig. 4 \& Fig. S1 in the Supplement at www.int-res.com/articles/suppl/m488p023_supp. pdf). Accordingly, shark, grouper, and snapper biomass had strongest correlations with the horizontal axis of the MDS plot (Spearman's r > 0.6; Fig. 3b). Most notably, shark biomass was an order of magnitude higher on Rongelap compared to Majuro (mean of 63.1 and $3.2 \mathrm{~kg}$ per SPC, respectively). In contrast, small-bodied herbivore and detritivore surgeonfishes doubled in numeric density and biomass on Majuro, while parrotfishes were halved ( $p<0.01$, for pairwise comparisons). These findings were highlighted by significant reductions in 3 common scraper-andexcavator genera (Chlorurus spp., Hipposcarus spp., and Cetoscarus spp.), and an overall dominance of fewer species (most notably the small surgeonfish Ctenochaetus cyanocheilus, but also 2 parrotfish, Scarus rubroviolaceus and S. ghobban; ANOSIM Rstatistic $=0.45, \mathrm{p}<0.001$; Fig. S2 in the Supplement). In contrast, planktivore surgeonfishes were lower in both numeric density ( $p<0.001, t$-test) and size on
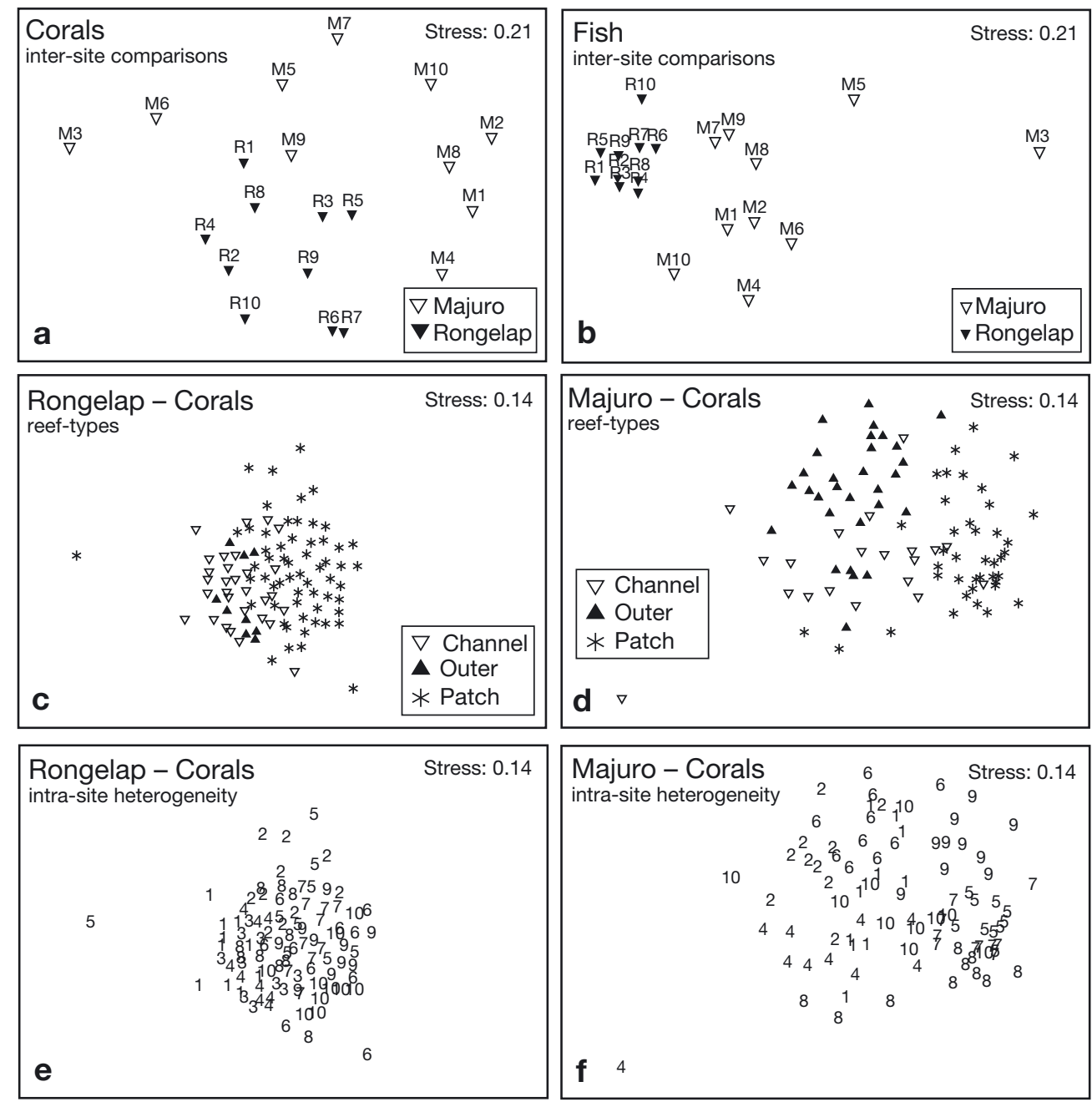

Fig. 3. Multi-dimensional scaling plots highlighting the differences between (a) coral and (b) fish assemblages from Majuro and Rongelap, based upon data aggregated at the site-level. In addition to clear differences in assemblage composition, assemblage heterogeneity (i.e. clustering of samples) also differed, as greater taxonomic distinction existed between sites on Majuro $(\mathrm{c}, \mathrm{d})$. Reef types were surrogates of coral assemblage heterogeneity, as reduced clustering was evident on Majuro in association with reef type. Yet, intra-site heterogeneity showed opposite patterns. Taxonomic differences between replicate measures of the coral assemblage within each site were higher with reduced human presence on (e) Rongelap compared with

(f) Majuro. Note: (e) and (f) represent the same MDS plots as (c) and (d), with numbers indicating site replicates 

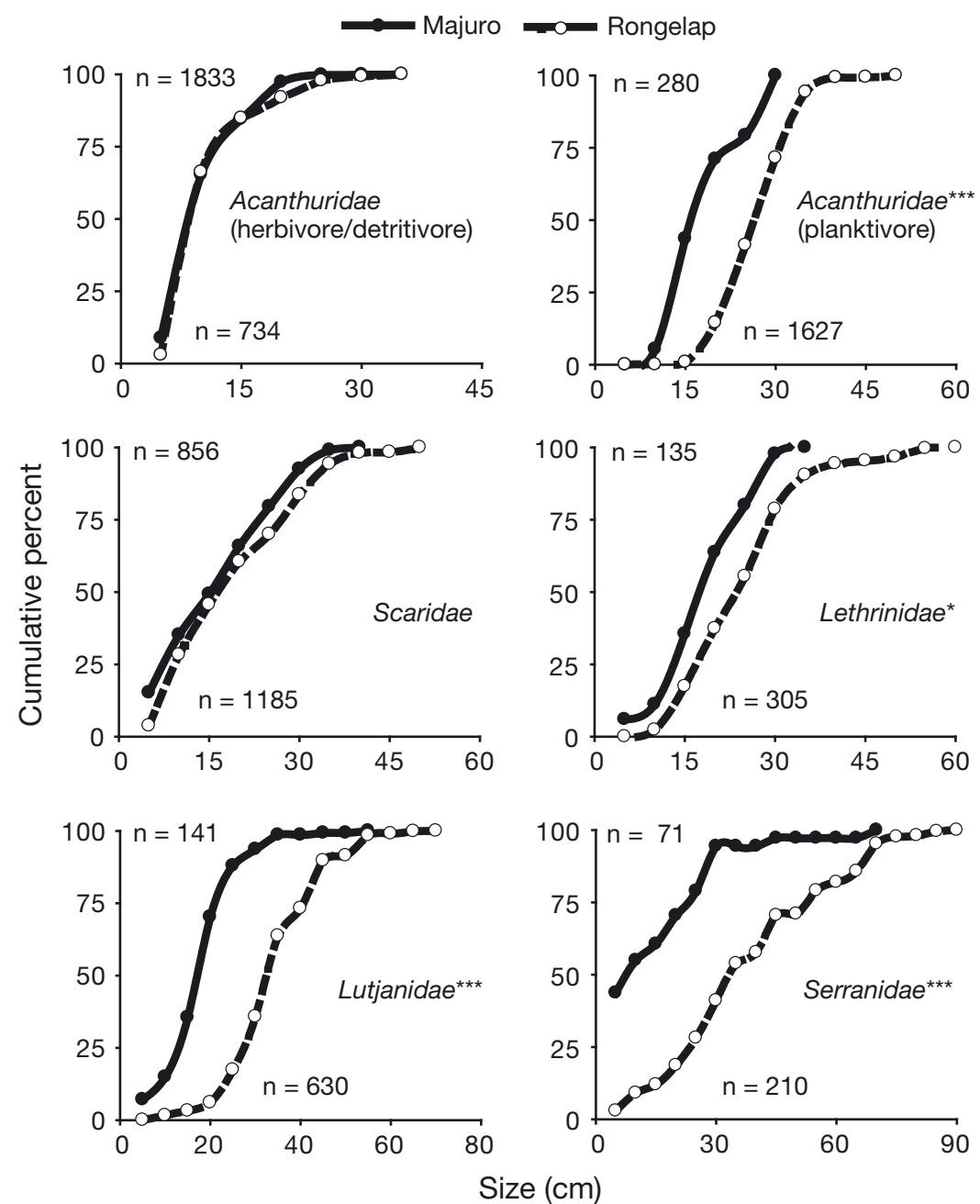

Fig. 4. Cumulative size-frequency distributions for dominant fish families observed on the study atolls. Sample sizes (n) for Majuro and Rongelap are provided at the top and bottom of each graph, respectively, and serve as a good indicator of overall biomass when considered alongside size-frequency distributions. Asterisks indicate differences between atolls (Kolmogorov-Smirnov tests, $\left.{ }^{*} \mathrm{p}<0.05,{ }^{* *} \mathrm{p}<0.01,{ }^{* * *} \mathrm{p}<0.001\right)$

Majuro ( $\mathrm{p}<0.001$, K-S test), mainly due to the absence of Naso hexacanthus, $N$. brevirostris, and $N$. annulatus.

In addition to compromised fish populations, increased opportunistic, non-calcifying algal substrates were found on Majuro $(\mathrm{p}<0.01, t$-test, ratio of non-calcifying versus calcifying substrates grouped; Fig. S3 in the Supplement) where turf, fleshy coralline, and macroalgae were more abundant, and crustose coralline algae was less abundant. Densities of encrusting and massive coral species were similar for both atolls ( $p>0.05, t$-tests), yet smaller colony sizes existed on Majuro ( $p<0.01, t$-tests). High-relief corals showed less overall difference in mean abundance, but greater variances on Majuro suggested that inter-site differences were larger (Fig. S4 in the Supplement). Growth form differences were supported by species composition trends. Reduced abundances of several staghorn Acropora, as well as A. palifera, A. c.f. tortuosa, A. florida, A. lovelli, and encrusting Montipora were found on Majuro, as the assemblages became more often dominated by Porites rus (Fig. S5 in the Supplement). Collectively, coral assemblage trends were well summarized by species accumulation patterns, as fewer species accounted for the majority of coral coverage on Majuro $(\mathrm{p}<0.01, t$-test between the slopes of cumulative dominance curves for Majuro and Rongelap; Fig. 5).

\section{Multivariate heterogeneity}

While fish and coral assemblages were clearly distinct between the 2 atolls, deeper examinations of multivariate heterogeneity facilitated an understanding of the mechanisms behind the degradation process. Larger inter-site heterogeneity was found for coral and fish assemblages on Majuro, indicating an increase in taxonomic isolation between sites where human influences were most pronounced ( $p<0.01, t$-tests between Bray-Curtis inter-site similarities for both corals and fishes between the 2 atolls; Fig. 3a,b). Reef types were associated with these trends for coral assemblages, as taxonomic isolation was attributed to greater distinctions between patch, channel, and outer reefs on Majuro (ANOSIM R-statistic $=0.51$ for coral assemblage difference between reef types, $p<0.01$ ) compared with Rongelap (ANOSIM R-statistic $<0.19$; Fig. 3c,d). Reef types were less influential predictors for inter-site food fish assemblage differences (ANOSIM R-statistic $<0.2$ for both atolls), which were better explained in accordance with proximity to human presence.

Opposite patterns emerged when examining the intra-site heterogeneity (i.e. taxonomic redundancy among replicate coral quadrats or fish SPC at any particular site). The mean Bray-Curtis similarity among replicate coral quadrats within each site was 


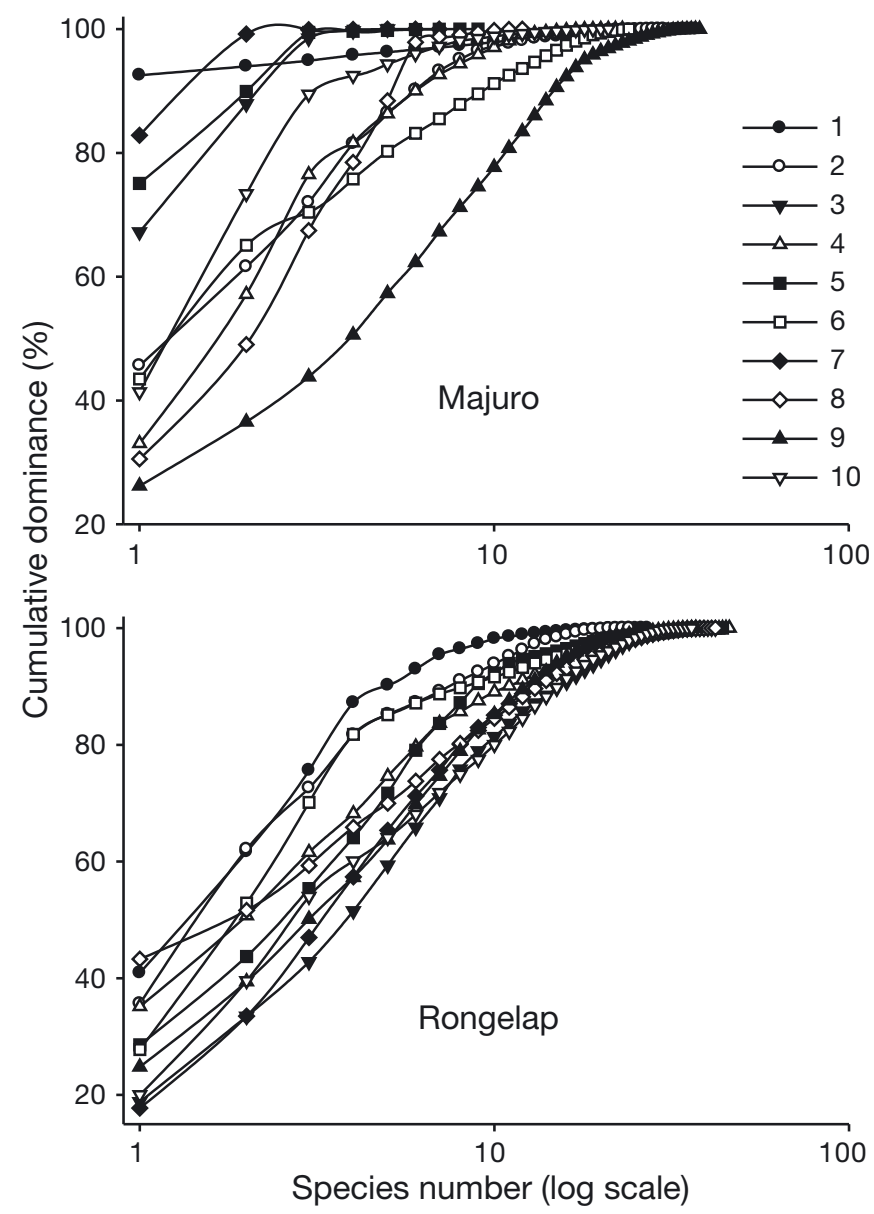

Fig. 5. Cumulative species-dominance distributions for coral assemblages at Majuro and Rongelap (legend numbers refer to site location; see Fig. 1)

significantly greater on Majuro compared with Rongelap ( $p=0.004, t$-test between similarities for corals between the 2 atolls; Fig. 3e,f), with a similar trend suggested for replicate fish SPC $(p=0.07, t$-test between intra-site similarities for fish). Thus, fewer species began to constitute more and more of the coral coverage and fish biomass within each site on Majuro, indicating a reduced network of species interactions.

Positive relationships between intra-site heterogeneity and human presence were strongest and most pronounced for fish assemblages along a gradient of distance from the sparse human population on Rongelap Atoll $\left(\mathrm{R}^{2}=0.42, \mathrm{p}<0.05\right.$, regression between distance and Bray-Curtis, intra-site similarity values; Fig. 6). Along this same gradient, there was also a significant, negative relationship between shark biomass and distance to humans $\left(R^{2}=0.74, p=\right.$ 0.02; Fig. 7), as well as a positive relationship between herbivore/detritivore size and distance to
Increasing distance from sparse human population (40 people)

\begin{tabular}{|cccc|}
\hline & 10 & & 2D Stress: 0.21 \\
$\begin{array}{c}\text { Large-bodied } \\
\text { grouper }\end{array}$ & & & \\
$\begin{array}{c}\text { Large-bodied } \\
\text { parrotfish }\end{array}$ \\
$\begin{array}{c}\text { Large-bodied } \\
\text { snapper }\end{array}$ \\
Shark
\end{tabular}

Fig. 6. Multi-dimensional scaling (MDS) plot highlighting growing intra-site heterogeneity (i.e. reduced clustering) for fish assemblages with distance from the sparse population on Rongelap Atoll (40 people). Numbers represent replicate stationary point count fish surveys within each monitoring site. Vectors indicate functional fish groups that were the strongest drivers of the MDS plot structure

humans $\left(\mathrm{R}^{2}=0.77, \mathrm{p}<0.001\right)$. The cumulative results indicated that human presence and/or apex predator biomass represented an origin for a series of linked trophic interactions.

\section{Linked trophic interactions}

Path analyses determined that 2 interaction chains had significantly higher covariance structures compared with independence models (Fig. 8), and were considered to represent trophic cascades that spanned across functional guilds within coral reef food webs. Foremost, human presence was negatively related to herbivore/detritivore size, herbivore/detritivore size was positively related to calcifying benthic substrates, and calcifying substrates were associated with reduced coral dominance $(\mathrm{p}=0.48, \mathrm{CFI}=1.00, \mathrm{RMSE}<0.01)$. Second, apex predator biomass was positively related to mean herbivore/detritivore size, herbivore/detritivore size was negatively related to non-calcifying benthic substrate, and non-calcifying substrates were positively related to coral dominance $(\mathrm{p}=0.38, \mathrm{CFI}=$ 0.99 , RMSE $=0.05$ ). Thus, humans and apex predators both represented origins for ensuing ecological cascades; however their roles were opposite as suggested by their negative correlation (Fig. 8 \& Fig. S6 in the Supplement). Notably, interaction chains that included direct relationships between human pres- 


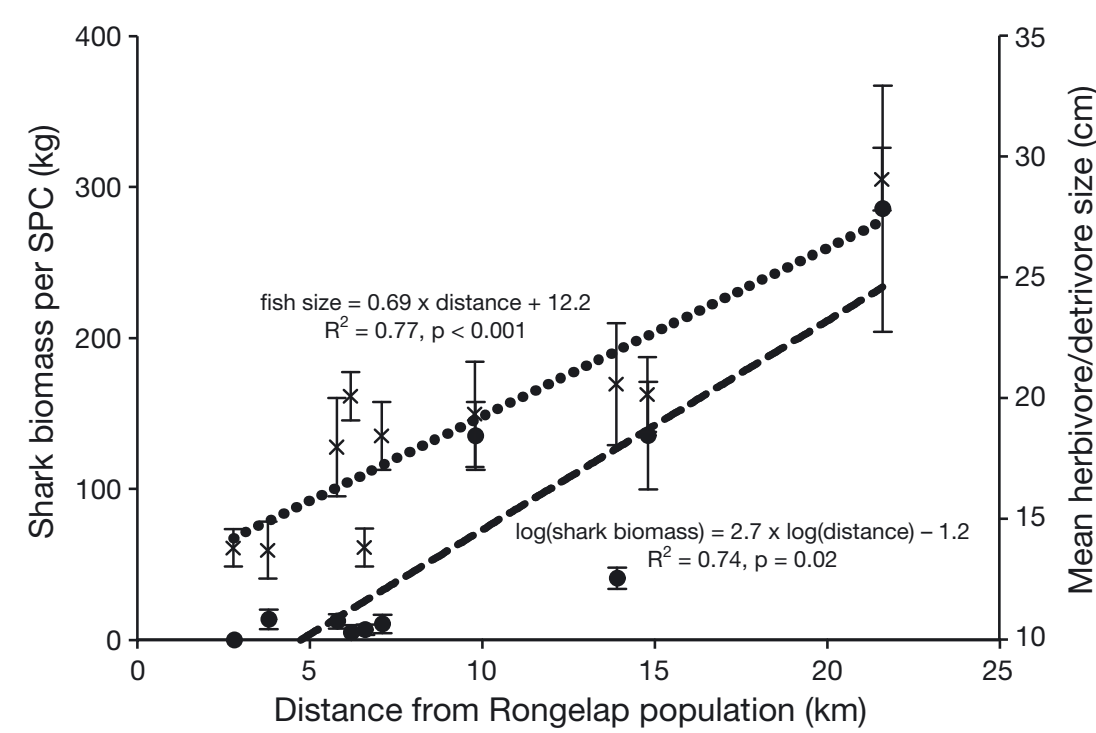

Fig. 7. Regression between mean $( \pm \mathrm{SE})$ shark biomass, herbivore/detritivore size, and distance from the sparse population on Rongelap Atoll (40 people). Best-fit models with the lowest Akaike Information Criterion scores are described in 'Results: Multivariate heterogeneity'. SPC: stationary point count

ence and apex predators as part of a larger, fully connected model explained less of the covariance structures as compared with the 2 models described above. In addition, no interaction chains that incorporated direct linkages between human influence and benthic substrates were found to be significant, suggesting that proxies for pollution were weaker drivers of ecological patterns in comparison to topdown influences.

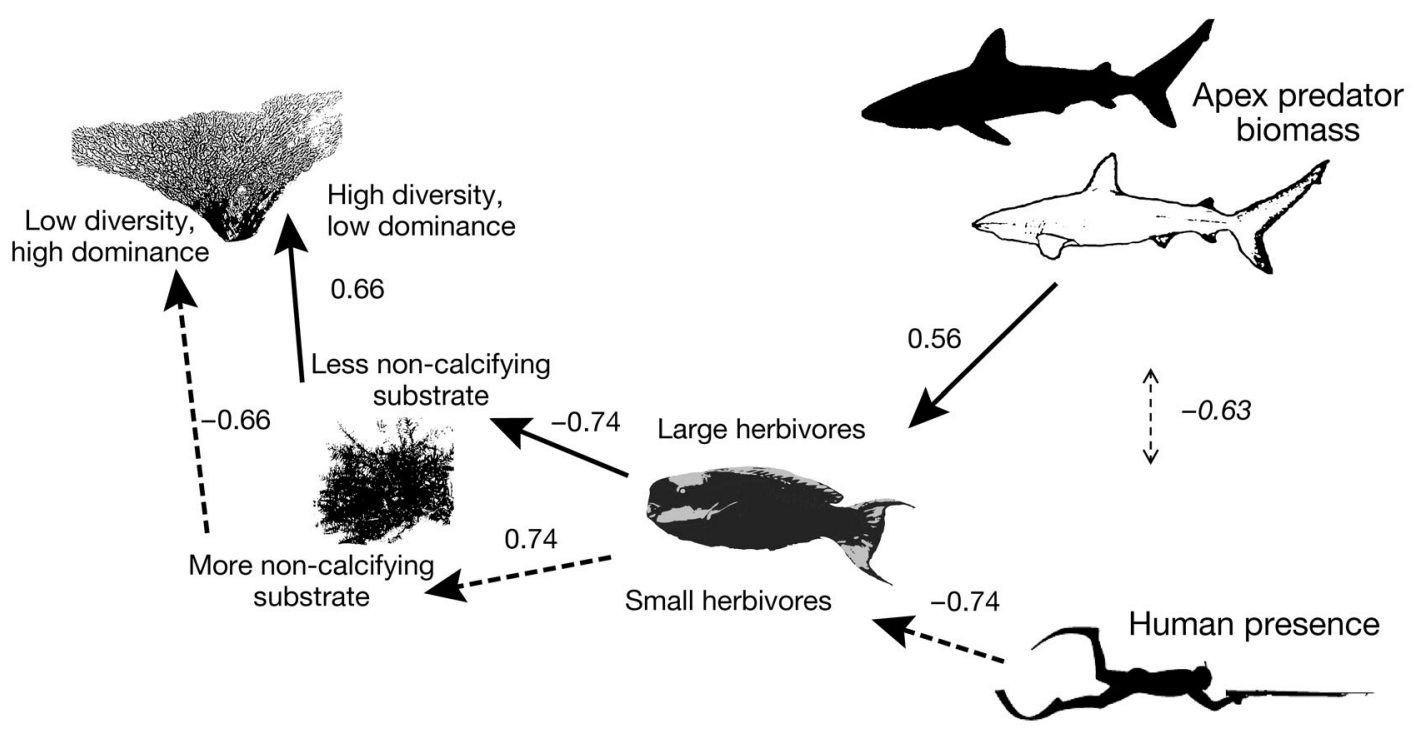

\section{DISCUSSION}

The present findings reinforce how sensitive many remote coral reef ecosystems are to human presence (Ferretti et al. 2010, Saavedra et al. 2011, Nadon et al. 2012). Apex predator biomass enhanced the size of herbivore/detritivore fish populations and provided benefits to the benthic and coral assemblages, while human presence, as low as 40 individuals, reduced fish size, calcifying substrates, and coral diversity in a predictable manner. Previous studies have linked apex predator biomass to larger grazing fish populations and reductions in fleshy algal biomass (Mumby et al. 2006, Newman et al. 2006), and have also linked enhanced grazing fish abundance inside marine protected areas with reduced algal substrate and improved coral cover (Mumby \& Harborne 2010). This study was unique in that we detected trophic interactions spanning 4 functional guilds associated with coral reef food webs. Central to our findings was the transition in herbivore/detritivore fish assemblages from being dominated by large-bodied parrotfish species that are less territorial, to being dominated by smaller-bodied parrotfishes and surgeonfishes with increased population

Fig. 8. Path analyses results highlighting 2 significant trophic cascades originating from (1) the positive influence of apex predator biomass on herbivore size (solid arrows) and (2) the negative influence of human presence on herbivore size (dashed arrows). Covariance structures of both models were significantly higher than independent models. Numbers associated with single-headed arrows indicate standardized regression coefficients, while the dashed double-headed arrow between apex predator biomass and human presence indicates their correlation coefficient 
densities (DeMartini et al. 2008). Thus, despite maintaining a similar or non-significant decline in overall herbivore assemblage biomass, many small fish had a reduced ecological function as compared with fewer large fish (Lokrantz et al. 2008), and as a result, top-down influences were disproportional drivers of the reported spatial gradients generated across both atolls.

Studies support that human presence acts concomitantly across predator and prey populations on coral reefs, and often represents the strongest driver of coral reef fish populations (Ferretti et al. 2010, Kellner et al. 2010, Williams et al. 2011). However, the negative relationships associated with human presence should be considered alongside the positive relationships that existed between apex predators, prey size, and prey-assemblage composition. Previous studies corroborate with and add detail to our finding that apex predators (1) preferentially selected small prey species that are easier to acquire (Emmerson \& Raffaelli 2004), (2) can promote diversity by switching their diet based upon prey abundances (Gross et al. 2009), and (3) indirectly provide benefits to larger prey that can escape the risk of predation (Mumby et al. 2006). In turn, larger prey are exponentially more efficient in performing their ecological functions (Lokrantz et al. 2008, Bellwood et al. 2012). Thus, while the roles of humans and apex predators were clearly opposing, predators had more complex interactions within food webs (McCann et al. 1998, Emmerson \& Raffaelli 2004). Human interactions were more ubiquitous and focused upon larger fish across all trophic levels that yield a greater payoff, in terms of food and monetary profit. In support of the subtle differences, path analyses found that the strongest trophic interactions originated from either human presence or apex predators (mainly sharks), but no significant model integrated both.

The collective results also provided empirical support describing how species with strong trophic interactions (i.e. species that accounted for high coral coverage or high fish biomass) were critical for maintaining food web structure (McCann et al. 1998, Neutel et al. 2002, Bascompte et al. 2005). As assemblages gravitated towards states with reduced intra-site heterogeneity, opportunistic and/or tolerant species that were less regulated through topdown processes became dominant. Eventually, coral reef assemblages became dominated by small acanthurids (Ctenochaetus cyanocheilus), non-calcifying substrates, and tolerant corals (Porites rus), indicating a reduction in functional resilience (i.e. ecological response time; Elmqvist et al. 2003), syno- nymous with food web networks that have low return rates to their modeled, stable configuration (i.e. low stability food webs; Neutel et al. 2002, 2007). In this sense, we consider ecological and mathematical stability to be synonymous, with stability being defined by the capacity of trophic guilds to return to stable, functional states following a perturbation (Neutel et al. 2002, 2007, Elmqvist et al. 2003). Therefore, integrating empirical data into models that predict stability, return times, and directional transitions may help to evaluate thresholds that are required for resilience.

While not formally approached, the present findings suggested that trophic downgrading contributed to the faster cycling of available nutrients through opportunistic organisms with high assimilation rates (i.e, faster growing turf and fleshy-algae substrates, faster growing acanthurid assemblages; McCook et al. 2001, Choat \& Robertson 2002). Freshwater studies found that fish assemblages with faster life cycles and less predator biomass had lower nutrient storage and faster, less continuous nutrient cycling in aquatic food webs (Vanni 2002, Emmerson \& Raffaelli 2004, Schmitz et al. 2010). Given that these findings resonate well with other systems and generalized theory (Halaj \& Wise 2002, Moore et al. 2004), further study of nutrient and detrital subsidies would also improve our understanding of coral reef trophic interactions.

\section{CONCLUSIONS}

For RMI atoll societies, marine resources contribute disproportionally to the livelihood and economic needs of the 68000 inhabitants, as ports have now become established on 9 atolls that facilitate monthly transport of harvested resources to Majuro-based markets. Our ability to understand, translate, and measure the consequences of harvesting regimes is fundamental for their improved management. Ecosystem-level approaches offer an improved perspective for interpreting the nature and magnitude of top-down processes resultant from harvesting. Ecosystem approaches are enhanced through examining remote settings where apex predator populations remain intact because they offer a deeper understanding of the inherent, natural interactions that drive coral reef ecosystems. Expanding the gradient of investigation across more of the remote atolls can help to refine the present relationships and developing thresholds of unacceptable change in the coral reef ecosystems upon which remote atoll societies depend. 
Acknowledgements. Funding for this research was provided through a grant administered by the Western Pacific Coral Reef Institute, Office of Research and Sponsored Programs, University of Guam. The Marshall Islands Conservation Society, the Marshall Islands Marine Resources Authority, and the College of the Marshall Islands were invaluable partners for all aspects of our project, from planning to fieldwork. Don Hess, Albon Ishoda, Henry Muller, Alex Peters, Kilom Ishiguro, Candice Guavis, and Milner Okney all contributed to ensure project success. Mayor James Matayoshi of Rongelap and the residents of Rongelap Atoll provided extensive logistical assistance for field activities. Finally, we are grateful to Rodney Camacho for assistance with benthic data development. Kommol tata (thank you) to all.

\section{LITERATURE CITED}

Anderson M, Gorley R, Clarke K (2008) PERMANOVA+ for PRIMER: guide to software and statistical methods. PRIMER-E, Plymouth

- Antonius A (1999) Metapeyssonnelia corallepida, a new coral-killing red alga on Caribbean Reefs. Coral Reefs 18:301-301

> Antonius A (2001) Pneophyllum conicum, a coralline red alga causing coral reef-death in Mauritius. Coral Reefs 19:418-418

Baird AH, Guest JR, Willis BL (2009) Systematic and biogeographical patterns in the reproductive biology of scleractinian corals. Annu Rev Ecol Evol Syst 40:551-571

Bascompte J, Melián CJ, Sala E (2005) Interaction strength combinations and the overfishing of a marine food web. Proc Natl Acad Sci USA 102:5443-5447

Beger M, Jacobson D, Pinca S, Richards Z and others (2008) The state of coral reef ecosystems of the Republic of the Marshall Islands. In: Waddell JE, Clarke AM (eds) The state of coral reef ecosystems of the United States and Pacific Freely Associated States: 2008. National Oceanic and Atmospheric Administration, Silver Springs, MD, p 387-417

Bellwood DR, Hoey AS, Hughes TP (2012) Human activity selectively impacts the ecosystem roles of parrotfishes on coral reefs. Proc R Soc Lond B Biol Sci 279:1621-1629

Bohnsack JA, Bannerot SP (1986) A stationary visual census technique for quantatively assessing community structure of coral reef fishes. National Oceanic and Atmospheric Administration Technical Report NMFS 41, Washington, DC

Box GEP, Cox DR (1964) An analysis of transformations. J R Stat Soc B 26:211-252

Choat JH, Robertson DR (2002) Age-based studies on coral reef fishes. In: Sale P (ed) Coral reef fishes: dynamics and diversity in a complex ecosystem. Academic Press, San Diego, CA, p 57-80

> DeMartini EE, Friedlander AM, Sandin SA, Sala E (2008) Differences in fish-assemblage structure between fished and unfished atolls in the northern Line Islands, central Pacific. Mar Ecol Prog Ser 365:199-215

Elmqvist T, Folke C, Nystrom M, Peterson G, Bengtsson J, Walker B, Norberg J (2003) Response diversity, ecosystem change, and resilience. Front Ecol Environ 1:488-494

Emmerson MC, Raffaelli D (2004) Predator-prey body size, interaction strength and the stability of a real food web. J Anim Ecol 73:399-409
Estes JA, Terborgh J, Brashares JS, Power ME and others (2011) Trophic downgrading of planet earth. Science 333:301-306

Ferretti F, Worm B, Britten GL, Heithaus MR, Lotze HK (2010) Patterns and ecosystem consequences of shark declines in the ocean. Ecol Lett 13:1055-1071

> Friedlander AM, DeMartini EE (2002) Contrasts in density, size, and biomass of reef fishes between the northwestern and the main Hawaiian islands: the effects of fishing down apex predators. Mar Ecol Prog Ser 230:253-264

Friedlander AM, Sandin SA, DeMartini EE, Sala E (2010) Spatial patterns of the structure of reef fish assemblages at a pristine atoll in the central Pacific. Mar Ecol Prog Ser 410:219-231

> Graham N, Dulvy N, Jennings S, Polunin N (2005) Sizespectra as indicators of the effects of fishing on coral reef fish assemblages. Coral Reefs 24:118-124

> Gross T, Rudolf L, Levin SA, Dieckmann U (2009) Generalized models reveal stabilizing factors in food webs. Science 325:747-750

Halaj J, Wise DH (2002) Impact of a detrital subsidy on trophic cascades in a terrestrial grazing food web. Ecology 83:3141-3151

Hiatt RW, Strasburg DW (1960) Ecological relationships of the fish fauna on coral reefs of the Marshall Islands. Ecol Monogr 30:65-127

> Houk P, van Woesik R (2006) Coral reef benthic video surveys facilitate long-term monitoring in the commonwealth of the Northern Mariana Islands: toward an optimal sampling strategy. Pac Sci 60:177-189

Houk P, van Woesik R (2010) Coral assemblages and reef growth in the Commonwealth of the Northern Mariana Islands (Western Pacific Ocean). Mar Ecol 31:318-329

Houk P, Musburger C, Wiles P (2010) Water quality and herbivory interactively drive coral-reef recovery patterns in American Samoa. PLoS ONE 5:e13913

Keats DW, Chamberlain YM, Baba M (1997) Pneophyllum conicum (Dawson) comb. nov. (Rhodophyta, Corallinaceae), a widespread Indo-Pacific non-geniculate coralline alga that overgrows and kills live coral. Bot Mar 40:263-279

Kellner JB, Litvin SY, Hastings A, Micheli F, Mumby PJ (2010) Disentangling trophic interactions inside a Caribbean marine reserve. Ecol Appl 20:1979-1992

> Knip DM, Heupel MR, Simpfendorfer CA (2012) Evaluating marine protected areas for the conservation of tropical coastal sharks. Biol Conserv 148:200-209

> Knowlton N, Jackson JBC (2008) Shifting baselines, local impacts, and global change on coral reefs. PLoS Biol 6:e54

Kohler KE, Gill SM (2006) Coral point count with Excel extensions (CPCe): A visual basic program for the determination of coral and substrate coverage using random point count methodology. Comput Geosci 32:1259-1269

Lokrantz J, Nystrom M, Thyresson M, Johansson C (2008) The non-linear relationship between body size and function in parrotfishes. Coral Reefs 27:967-974

> McCann K, Hastings A, Huxel GR (1998) Weak trophic interactions and the balance of nature. Nature 395: 794-798

> McClanahan TR, Graham NAJ, Calnan JM, MacNeil MA (2007) Toward pristine biomass: reef fish recovery in coral reef marine protected areas in Kenya. Ecol Appl 17:1055-1067

> McCook L, Jompa J, Diaz-Pulido G (2001) Competition 
between corals and algae on coral reefs: a review of evidence and mechanisms. Coral Reefs 19:400-417

Moore JC, Berlow EL, Coleman DC, Ruiter PC and others (2004) Detritus, trophic dynamics and biodiversity. Ecol Lett 7:584-600

Mumby PJ, Harborne AR (2010) Marine reserves enhance the recovery of corals on Caribbean reefs. PLoS ONE 5: e8657

Mumby PJ, Dahlgren CP, Harborne AR, Kappel CV and others (2006) Fishing, trophic cascades, and the process of grazing on coral reefs. Science 311:98-101

Mumby PJ, Harborne AR, Williams J, Kappel CV and others (2007) Trophic cascade facilitates coral recruitment in a marine reserve. Proc Natl Acad Sci USA 104:8362-8367

Myers RA, Baum JK, Shepherd TD, Powers SP, Peterson CH (2007) Cascading effects of the loss of apex predatory sharks from a coastal ocean. Science 315:1846-1850

- Nadon MO, Baum JK, Williams ID, Mcpherson JM and others (2012) Re-creating missing population baselines for Pacific reef sharks. Conserv Biol 26:493-503

Neutel AM, Heesterbeek JAP, de Ruiter PC (2002) Stability in real food webs: weak links in long loops. Science 296: $1120-1123$

Neutel AM, Heesterbeek JAP, Van de Koppel J, Hoenderboom G and others (2007) Reconciling complexity with stability in naturally assembling food webs. Nature 449: 599-602

Newman MJH, Gustavo AP, Sala E, Jackson JBC (2006) Structure of Caribbean coral reef communities across a large gradient of fish biomass. Ecol Lett 9:1216-1227

Nyström M (2006) Redundancy and response diversity of functional groups: implications for the resilience of coral reefs. Ambio 35:30-35

Pinca S, Beger M, Jacobson D, Keju T (2005) The state of coral reef ecosystems of the Marshall Islands. In: Waddell $\mathrm{J}$ (ed) The state of coral reef ecosystems of the United States and Pacific Freely Associated States. National Oceanic and Atmospheric Administration, Silver Springs, MD, p 373-386

R Development Core Team (2005) R: a language and environment for statistical computing, reference index v. 2.2.1. R Foundation for Statistical Computing, Vienna. www.R-project.org (accessed May 2012)

Editorial responsibility: Janet Ley, St. Petersburg, Florida, USA
Richards ZT, Beger M, Pinca S, Wallace CC (2008) Bikini Atoll coral biodiversity resilience five decades after nuclear testing. Mar Pollut Bull 56:503-515

Rooney N, McCann K (2011) Integrating diversity, food web structure and stability. Trends Ecol Evol 27:40-46

Rooney N, McCann K, Gellner G, Moore JC (2006) Structural asymmetry and the stability of diverse food webs. Nature 442:265-269

Rosseel Y (2012) Package 'lavaan'. Latent variable analysis for R. http://lavaan.org (accessed September 2012)

Saavedra S, Stouffer DB, Uzzi B, Bascompte J (2011) Strong contributors to network persistence are the most vulnerable to extinction. Nature 478:233-235

Sandin SA, Smith JE, DeMartini EE, Dinsdale EA and others (2008) Baselines and degradation of coral reefs in the northern Line Islands. PLoS ONE 3:e1548

> Schmitz OJ, Hawlena D, Trussell GC (2010) Predator control of ecosystem nutrient dynamics. Ecol Lett 13: 1199-1209

> Simon SL (1997) A brief history of people and events related to atomic weapons testing in the Marshall Islands. Health Phys 73:5-20

> Smith JE, Hunter CL, Smith CM (2010) The effects of topdown versus bottom-up control on benthic coral reef community structure. Oecologia 163:497-507

Stevenson C, Katz LS, Micheli F, Block B and others (2007) High apex predator biomass on remote Pacific islands. Coral Reefs 26:47-51

Vanni MJ (2002) Nutrient cycling by animals in freshwater ecosystems. Annu Rev Ecol Syst 33:341-370

Veron J (2000) Corals of the world. Australian Institute of Marine Science, Townsville

Wells JW (1954) Recent corals of the Marshall Islands. Bikini and nearby atolls, Part 2, Oceanography. US Geological Survey Professional Paper 260-I, Washington, DC

Williams ID, Richards BL, Sandin SA, Baum JK and others (2011) Differences in reef fish assemblages between populated and remote reefs spanning multiple archipelagos across the central and western Pacific. J Mar Biol 2011: 826234

> Woodward G, Ebenman B, Emmerson M, Montoya JM, Olesen JM, Valido A, Warren PH (2005) Body size in ecological networks. Trends Ecol Evol 20:402-409

Submitted: January 16, 2013; Accepted: May 16, 2013

Proofs received from author(s): July 30, 2013 